\title{
Hisse Fiyatları ile Yabancı Yatırımcı Ticareti Arasındaki İlişki: Borsa İstanbul'da İşlem Gören Bankalar Üzerine Bir Uygulama \\ (The Relationship between Stock Prices and Foreign Investor Trading: An Application to Banks Listed in Borsa Istanbul)
}

\section{Bekir KAYA iD a}

a Ankara Hacı Bayram Veli Üniversitesi, Polatlı Sosyal Bilimler Meslek Yüksekokulu, Muhasebe ve Vergi Bölümü, Ankara, Türkiye. bekir.kaya@hbv.edu.tr

\begin{tabular}{|c|c|}
\hline MAKALE BİLGİSİ & ÖZET \\
\hline Anahtar Kelimeler: & Amaç - Bu çalışmada Ocak 2000 - Aralık 2018 dönemi arasında Borsa İstanbul'da listelenen bankalar \\
\hline Eşbütünleşme & $\begin{array}{l}\text { ölçeğinde yabancı yatırımcı alım-satım işlemleri ile hisse fiyatları arasındaki ilişkinin incelenmesi } \\
\text { amaçlanmaktadır. }\end{array}$ \\
\hline Nedensellik & Yöntem - Eşbütünleşme iliškisinin belirlenmesi için panel eşbütünleşme testi, nedensellik ilişkisinin \\
\hline Yabanc1 Yatırımcı Ticareti & belirlenmesi için panel nedensellik testi uygulanmıştır. \\
\hline Hisse Fiyatları & $\begin{array}{l}\text { Bulgular - Panel eşbütünleşme testinin sonuçları, yabancı yatırımcı ticareti ile hisse senedi fiyatları } \\
\text { arasında uzun dönem eşbütünleşme ilişkisinin varlığını göstermektedir. Tahmin edilen uzun } \\
\text { dönemli esneklikler, yabancı yatırımcı alımlarının hisse fiyatları üzerinde istatistiki olarak anlamlı }\end{array}$ \\
\hline $\begin{array}{l}\text { Gönderilme Tarihi } 12 \text { Eylül } \\
2019\end{array}$ & $\begin{array}{l}\text { pozitif bir etkiye, yabancı yatırımcı satışlarının hisse fiyatları üzerinde istatistiki olarak anlamlı } \\
\text { negatif bir etkiye sahip olduğunu göstermektedir. Panel nedensellik testinin bulguları, hisse }\end{array}$ \\
\hline Revizyon Tarihi 12 Mart 2020 & $\begin{array}{l}\text { fiyatlarından yabancı yatırımcı satışlarına doğru tek yönlü nedensellik ilişkisi olduğunu } \\
\text { göstermektedir. }\end{array}$ \\
\hline Kabul Tarihi 20 Mart 2020 & $\begin{array}{l}\text { Tartışma - Eşbütünleşme testi sonuçları değişkenlerin uzun dönemde birlikte hareket ettiğini } \\
\text { göstermektedir. Bu sonuçlara göre yabancı yatırımcı alım-satımları ile hisse fiyatları uzun dönemde }\end{array}$ \\
\hline $\begin{array}{l}\text { Makale Kategorisi: } \\
\text { Araştırma Makalesi }\end{array}$ & $\begin{array}{l}\text { birlikte hareket etmektedir. Kısa dönemde ilişkinin yönü ile ilgili değerlendirmeler için nedensellik } \\
\text { testleri yapılmaktadır. Nedensellik testi sonuçları, hisse senedi fiyatlarındaki değişimin yabancı } \\
\text { yatırımcıların satışlarının nedeni olduğunu göstermektedir. }\end{array}$ \\
\hline
\end{tabular}

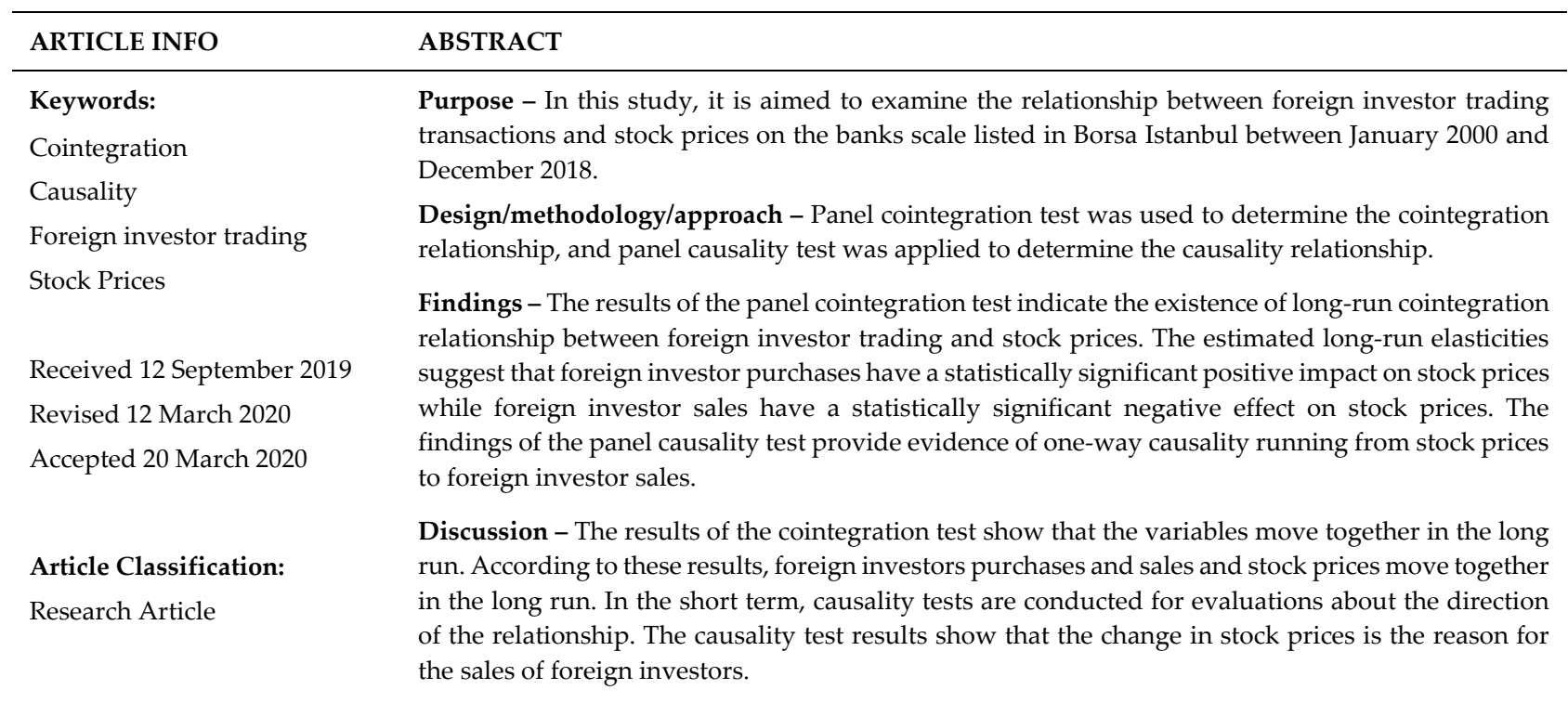




\section{GíRiş}

Literatürde yabancı yatırımcı işlemleri ile hisse fiyatları arasındaki ilişkiyi inceleyen çalışmaları iki açıdan gruplandırabilmek mümkündür. Birinci grup çalışmalarda hisse fiyatlarının yabancı yatırımcıların alımsatımları üzerindeki etkisi incelenmiştir. Hisse fiyatlarının yabancı yatırımcıların alım-satımları üzerindeki etkisi, pozitif geri besleme hipotezi ve negatif geri besleme hipotezi ile açıklanabilmektedir. Pozitif geri besleme hipotezine göre, yatırımcılar hisse fiyatları arttığında satın almakta, hisse fiyatları düştüğünde satmaktadır (Choe vd., 1999:229). Negatif geri besleme hipotezine göre ise, yatırımclar hisse fiyatları arttığında satmakta, hisse fiyatları düştüğünde ise, satın almaktadır (Nofsinger ve Sias, 1999:2266). Choe vd. (1999), Samarakoon (2009), Jeon ve Moffet (2010), Phansatan vd. (2012), Porras ve Ülkü (2015), Dhingra vd. (2016), Vo (2017), Junior ve Junior (2017) tarafından yapılan çalışmalarda yabancı yatıımcıların pozitif geri besleme hipotezine uygun hareket ettiği sonucuna ulaşılmıştır. Akar (1997), Ülkü ve İkizlerli (2012), Ülkü (2015), Dhingra vd. (2016) tarafından yapılan çalışmalarda ise, yabancı yatırımcıların negatif geri besleme hipotezine uygun hareket ettiğini destekleyen bulgulara ulaşılmıştır. İkinci grup çalışmalarda ise, yabancı yatırımcıların alım-satım işlemlerinin hisse fiyatları üzerindeki etkisi incelenmiştir. Yabancı yatırımcıların alımlarının hisse fiyatlarını artırması, satışlarının ise hisse fiyatlarını düşürmesi beklentisine rağmen çalışmalarda elde edilen bulgular farklılaşmaktadır. Chiang vd. (2012) Tayvan borsasında yaptıkları çalışmalarında, yabancı yatırımcıların alımlarının hisse fiyatlarını artırdığı sonucuna ulaşmıştır. Vo (2017) tarafından Vietnam borsasında gerçekleştirilen çalışmada yabancı yatırımcıların alımlarının hisse fiyatlarını üzerindeki etkisinin negatif, satışlarının ise pozitif olduğu sonucuna ulaşılmıştır. Literatürde Borsa İstanbul'da gerçekleştirilen yabancı yatırımcı işlemlerine ilişkin çalışmalara da yer verilmektedir. Bolaman Avcı (2015)'nın çalışmasında yabancı işlemleri ile endeks arasında eşbütünleşme ilişkisi incelenmiştir. Analiz sonuçlarına göre eşbütünleşme ilişkisi tespit edilmiştir. Yabancı yatırımcı işlemleri ile endeks getirileri arasında nedenselliğin yönünü incelemeye yönelik yapılan analizler de ise, Bolaman Avcı (2015) alım satım işlemlerinden hisse getirilerine doğru tek yönlü nedensellik, Akar (1997) hisse getirilerinden net yabancı işlemlerine doğru tek yönlü nedensellik tespit etmiştir. Yapılan bu çalışmanın, bir sektör ölçeğinde olması diğer çalışmalardan ayrılan yönünü oluşturmaktadır. Nitekim daha önce yapılan çalışmalarda Borsa İstanbul geneli için ulaşılan sonuçlara yer verildiği, bir sektör ölçeğinde çalışma yapılmadığı görülmüştür. Borsa İstanbul'un lokomotifi konumundaki bankacılık sektörü için yapılan bu çalışmanın diğer çalışmalardan farklılık yaratacağı ve literatüre katkı sağlayacağı düşünülmektedir.

Çalışmanın ilerleyen kısımlarında amacı-önemi, yöntemi, bulguları, sonuç ve tartışma bölümlerine yer verilmiştir.

\section{2. ÇALIŞMANIN AMACI-ÖNEMI}

Bu çalışmada Ocak 2000 ve Aralık 2018 dönemi arasında Borsa İstanbul'da işlem gören bankalar ölçeğinde yabancı yatırımcı alım-satım işlemleri ile hisse fiyatları arasındaki ilişkinin incelenmesi amaçlanmaktadır. Bu amacın ortaya konulmasında yabancı yatırımcı işlemlerinin Borsa İstanbul'da (özellikle de bankacılık sektöründe) etkinliğinin artması önemli bir nedeni oluşturmaktadır. Merkezi Kayıt Kuruluşu verilerine göre ${ }^{1}$; 2018 yılı sonu itibariyle yabancı yatırımcıların Borsa İstanbul'daki şirketlerin piyasa değerinin \%65'ine sahiptir. Yabancı yatırımcıların elindeki hisselerin piyasa değeri 204 milyar TL seviyesinde iken, yerli yatırımclar da ise bu tutar 111 milyar TL düzeyindedir. Bu veriler yabancı yatırımcıların Borsa İstanbul içindeki payının önemli seviyelerde olduğunu göstermektedir. 2018 yılı sonunda Borsa İstanbul'da işlem hacmi bir önceki yıla göre \%21 artmış ve 2 katrilyon TL seviyesine yaklaşmıştır. Bu artış içerinde en yüksek pay ise BIST BANKA endeksindeki şirketlerde gerçekleşmiştir. BIST BANKA endeksinde işlem hacmi 2017 yılında 50,67 milyar TL iken 2018 yılında yaklaşık \%84 artışla 93,19 milyar TL seviyesine ulaşmıştır. 2018 yılında BIST BANKA endeksindeki şirketlerin portföy değeri içinde yabancı yatırımcıların payı yerli yatırımcılara nazaran daha fazladır. Aralık 2018 itibariyle BIST BANKA endeksi kapsamında yerli yatırımcının portföy değeri 18 milyar TL iken yabancı yatırımcının portföy değeri 68 milyar TL'dir. Bu bilgilerden hareketle yabancı yatırımcılar tarafından gerçekleştirilen alım-satım işlemlerinin BIST BANKA hisselerinde fiyatların belirlenmesi noktasındaki etkisi dikkat çekicidir.

\footnotetext{
${ }^{1}$ Merkezi Kayıt Kuruluşu, Borsa Trenleri Raporları, XXVII, Erişim: https://www.mkk.com.tr/tr/content/BilgiMerkezi/Borsa-Trendleri-Raporu, Erişim Tarihi: 11.06.2019.
} 


\section{YÖNTEM}

Çalışmada kullanılan veriler, Ocak 2000 ile Aralık 2018 arasındaki 216 aylık dönemi kapsamaktadır. Çalışmada bu dönemin tamamında Borsa İstanbul BIST BANKA endeksinde işlem gören 5 bankaya ${ }^{2}$ ilişkin hisse fiyatı, yabancı yatırımcı alım-satım işlemlerine ilişkin seriler kullanılmıştır. Söz konusu dönemde 13 banka hissesi Borsa İstanbul'da işlem görmüştür. Fakat bankaların Borsa İstanbul'da işlem görmeye başladıkları dönemler farklılaşmaktadır. Bu durum dengesiz paneller elde edilmesine neden olmakta ve ulaşılan sonuçları olumsuz etkilemektedir. Dengeli bir panel veri setinin kullanılabilmesi için 13 banka içerisinden araştırma döneminin tamamında Borsa İstanbul'da işlem gören 5 bankaya ilişkin seriler kullanılmıştır. Bu durum çalı̧̧manın bir kısıtını oluşturmaktadır. Çalışmada kullanılan veriler Borsa İstanbul ${ }^{3}$ dan temin edilmiştir. Veriler logaritmik dönüşüme tabi tutularak analiz sürecine alınmıştır.

Temel denklem (1) şöyle oluşturulmuştur:

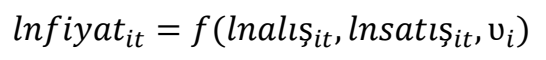

Denklemde bağımlı değişken lnfiyatit banka hisse fiyatlarını, lnalışit yabancı yatırımcı alış işlemlerini ve lnsatışit yabancı yatırımcı satış işlemlerini ifade etmektedir. $v_{i}$ bireysel sabit banka etkilerini göstermektedir. Bankalar i $(\mathrm{i}=1, \ldots . ., \mathrm{n})$ göstergesi ile ifade edilirken, zaman $\mathrm{t}(\mathrm{t}=1, \ldots \ldots ., \mathrm{t})$ göstergesi ile ifade edilmektedir.

Çalışmada yapılan analizler beş aşamada tamamlanmıştır. İlk aşamada yatay kesit bağımlılığın belirlenmesi için yatay kesit bağımlılık testleri yapılmaktadır. İkinci aşamada serilerin durağanlık düzeylerinin belirlenmesi için panel birim kök testi yapılmaktadır. Üçüncü aşamada değişkenler arasındaki uzun dönemli ilişkisinin belirlenmesi için eşbütünleşme testi yapılmaktadır. Dördüncü aşamada değişkenler arasındaki uzun dönem ve kısa dönem ilişkinin katsayıları yapılan testler ile belirlenmektedir. Son aşamada yapılan nedensellik testiyle, değişkenler arasındaki nedensellik ilişkisi belirlenmektedir.

\subsection{Yatay Kesit Bağımlılık Testleri}

Yatay kesit bağımlılığın varlığı, serilerin durağanlığının belirlenmesi için kullanılacak panel birim kök testlerini tercih ederken önem taşımaktadır. Birinci kuşak panel birim kök testleri seriler arasında yatay kesit bağımlılık olmadığını varsayarken, ikinci kuşak panel birim kök testleri seriler arasında yatay kesit bağımlılık olması durumunda uygulanmaktadır. Seriler arasında yatay kesit bağımlılığın belirlenmesi için BreuschPagan (1980) LM test, Pesaran (2004) scaled LM test, Baltagi vd. (2012) bias-corrected scaled LM test ve Pesaran (2004) CD test uygulanmıştır.

\subsection{Panel Birim Kök Testleri}

Birinci kuşak panel birim kök testlerine; Levin vd. (2002), Harris ve Tzavalis (1999), Breitung (2000), Hadri (2000), Im vd. (2003), Fisher ADF (Maddala ve Wu, 1999) örnek verilebilir. Eğer seriler arasında yatay kesit bağımlılık varsa bu testlerin gücü zayıflamaktadır (Tatoğlu, 2013:199). Birimler arasında yatay kesit bağımlılığın varlığı durumunda ise, ikinci kuşak panel birim kök testleri uygulanmaktadır. İkinci kuşak panel birim kök testlerine; Moon ve Perron (2004), Phillips ve Sul (2002), Bai ve Ng (2004) ve Pesaran (2007) örnek verilebilir.

Çalışmadaki serilerde yatay kesit bağımlılık tespit edildiğinden ikinci kuşak panel birim kök testlerinden Pesaran (2007) CADF (Yatay Kesit Genelleştirilmiş Dickey Fuller) testi uygulanmıştır. Pesaran (2007) CADF panel birim kök testi uygulanırken gecikme uzunluğunun belirlenmesi gerekmektedir. Belirlenen gecikme uzunluğu test sonuçlarını etkilemektedir. Gecikme uzunluğu, bir bilgi kriteri ile ya da ardışık testlerle seçilebilmektedir (Tatoğlu, 2013:224; Burret vd., 2016:8).

\subsection{Panel Eşbütünleşme Testi}

Birim kök içeren değişkenlerin doğrusal bileşimlerinin durağan olması durumunda, seriler arasında uzun dönemli ilişki olabilmektedir (Tatoğlu, 2013:233). Seriler arasındaki uzun dönemli ilişkinin varlığı, panel eşbütünleşme testleri ile incelenmektedir. Panel eşbütünleşme testlerine; Kao (1999), Pedroni (1999, 2004), McCoskey ve Kao (1998) ve Westerlund (2007) örnek verilebilir. Bu çalışmada Westerlund (2007) tarafından

\footnotetext{
${ }^{2}$ Akbank T.A.Ş., Türkiye Garanti Bankası A.Ş., Türkiye İş Bankası A.Ş., QNB Finansbank A.Ş., Yapı ve Kredi Bankası A.Ş.

3 https://datastore.borsaistanbul.com/ , Erişim Tarihi: 30/04/2019.
} 
geliştirilen panel eşbütünleşme testi kullanılmıştır. Bu testin tercih edilmesinin nedeni sağladığı avantajlardan kaynaklanmaktadır. Çünkü Westerlund (2007) panel eşbütünleşme testi, birimler arası yatay kesit bağımlılığın olması durumunda dirençli kritik değerleri özçıkarım sonucu elde edebilmektedir (Tatoğlu, 2013: 240). Westerlund (2007) panel eşbütünleşme testinde, eşbütünleşmenin varlığı hata düzeltme modeli temelli $\mathrm{P}_{\mathrm{a}}, \mathrm{P}_{\mathrm{t}}$, $\mathrm{G}_{a}$ ve $\mathrm{G}_{t}$ istatistikleri hesaplanarak belirlemektedir. Bu istatistiklerle $\mathrm{H}_{0}$ : Eşbütünleşme ilişkisi yoktur. ve $\mathrm{H}_{1}$ : Eşbütünleşme ilişkisi vardır. hipotezleri sınanmaktadır.

\subsection{Panel Eşbütünleşme Regresyonları}

Eşbütünleşme ilişkisi tespit edilen serilerde uzun dönem ilişkinin belirlenmesinde çeşitli yöntemler kullanılabilmektedir. Bu yöntemlerden Tam Değiştirilmiş En Küçük Kareler ve Panel Dinamik En Küçük Kareler tahmincileri sadece uzun dönem parametreleri tahmin etmek için kullanılmaktadır. Havuzlanmış Ortalama Grup Tahmincisi, Ortalama Grup Tahmincisi ve Dinamik Sabit Etkiler Tahmincisi ise hem kısa hem de uzun dönem parametreleri tahmin etmektedir. Dinamik Sabit Etkiler Tahmincisi, hata düzeltme modelini sabit etkiler yardımıyla tahmin ettiği ve tüm parametreleri sabit tuttuğu için panele dahil edilen birimlere göre hesaplama yapmamaktadır (Tatoğlu, 2013:244). Havuzlanmış Ortalama Grup Tahmincisi ile Ortalama Grup Tahmincisi birimlere göre hesaplama yapılmasını mümkün kılmaktadır. Havuzlanmış Ortalama Grup Tahmincisi ile Ortalama Grup Tahmincisi arasında seçim yapabilmek için ise Hausman Testi kullanılabilmektedir (Tatoğlu, 2013:255).

\subsection{Heterojen Panel Nedensellik Testi}

Değişkenler arasındaki dinamik nedensellik ilişkisi Dumitrescu ve Hurlin (2012) tarafından geliştirilen heterojen panel nedensellik testi ile incelenmiştir. Bu yaklaşım tüm katsayıların kesit boyunca farklı olmasını sağlayan, yatay kesit bağımsızlığı dikkate alan, geleneksel nedensellik testlerinden farklılaşmaktadır (Paramati vd., 2017:11). Değişkenlerdeki yatay kesit bağımlılığı dikkate alarak daha dirençli ve güvenilir sonuçlar sağlamaktadır. Testin uygulanmasının basit olması, çok küçük zaman ve gözlem boyutlarında uygulanabilmesi avantajları arasında sayılmaktadır (Dumitrescu ve Hurlin, 2012:1459).

\section{BULGULAR}

Yatay kesit bağımlılık testlerine, panel birim kök testine, panel eşbütünleşme testine, panel eşbütünleşme regresyonlarına, heterojen panel nedensellik testine ilişkin sonuçlara aşağıdaki kısımlarda yer verilmiştir.

\subsection{Yatay Kesit Bă̆ımlılık Testleri}

Yatay kesit bağımlılığın belirlenmesi için yapılan testlerin sonuçları Tablo 1'de yer almaktadır.

Tablo 1. Yatay Kesit Bağımlılık Testlerinin Sonuçları

\begin{tabular}{|l|c|c|c|}
\hline \multirow{2}{*}{\multicolumn{1}{|c|}{ Test }} & \multicolumn{3}{|c|}{ Değişkenler } \\
\cline { 2 - 4 } & lnalış & lnsatış & lnfiyat \\
\hline Breusch-Pagan LM & $1156.686^{* * *}$ & $1200.246^{* * *}$ & $616.6849^{* * * *}$ \\
\hline Pesaran scaled LM & $256.4068^{* * * *}$ & $266.1470^{* * * *}$ & $135.6589^{* * * *}$ \\
\hline Bias-corrected scaled LM & $256.3958^{* * *}$ & $266.1360^{* * *}$ & $135.6479^{* * * *}$ \\
\hline Pesaran CD & $16.94308^{* * *}$ & $16.60258^{* * *}$ & $22.08742^{* * * *}$ \\
\hline
\end{tabular}

Notes. ${ }^{* * *} \% 1$ düzeyinde istatistiki olarak anlamlılığı göstermektedir.

Tablo 1'deki sonuçlara göre, seriler arasında yatay kesit bağımlılık olmadığına dair $\mathrm{H}_{0}$ hipotezi \%1 anlamlılık düzeyinde reddedilmiş, $\mathrm{H}_{1}$ hipotezi kabul edilmiştir. Yani seriler arasında yatay kesit bağımlılık bulunmaktadir.

\subsection{Panel Birim Kök Testi}

Pesaran (2007) CADF panel birim kök testi 0-4 gecikme uzunluğu için yapılan ardışık testlerde elde edilen sonuçlar Tablo 2'de yer almaktadır. 
B. Kaya $12 / 1$ (2020) 705-714

Tablo 2. Pesaran (2007) CADF Testi Sonuçları

\begin{tabular}{|c|c|c|c|c|}
\hline \multirow{3}{*}{ Birim Kök Testleri } & $\begin{array}{c}\text { Gecikme } \\
\text { Uzunluğu }\end{array}$ & $\begin{array}{c}\text { lnalış } \\
\text { Z[t-bar] }\end{array}$ & $\begin{array}{c}\text { lnsatış } \\
\text { Z[t-bar] }\end{array}$ & $\begin{array}{c}\text { lnfiyat } \\
\text { Z[t-bar] }\end{array}$ \\
\hline \multirow{4}{*}{ Düzey } & 0 & $-6.879^{* * *}$ & $-6.321^{* * *}$ & $-4.061^{* * *}$ \\
\cline { 2 - 5 } & 1 & $-3.483^{* * *}$ & $-3.727^{* * *}$ & $-4.162^{* * *}$ \\
\cline { 2 - 5 } & 2 & $-1.469^{*}$ & $-2.481^{* * *}$ & $-3.509^{* * *}$ \\
\cline { 2 - 5 } & 3 & $-0,929$ & $-1.357^{*}$ & $-2.219^{* * *}$ \\
\cline { 2 - 5 } & 4 & 0,043 & -0.126 & $-1.662^{* * *}$ \\
\hline \multirow{4}{*}{ Birinci Fark } & 0 & $-10.932^{* * *}$ & $-10.932^{* * *}$ & $-10.932^{* * *}$ \\
\cline { 2 - 5 } & 1 & $-10.932^{* * *}$ & $-10.932^{* * *}$ & $-10.932^{* * *}$ \\
\cline { 2 - 5 } & 2 & $-10.932^{* * *}$ & $-10.932^{* * *}$ & $-10.932^{* * *}$ \\
\cline { 2 - 5 } & 3 & $-10.932^{* * *}$ & $-10.932^{* * *}$ & $-10.932^{* * * *}$ \\
\cline { 2 - 5 } & 4 & $-10.932^{* * *}$ & $-10.932^{* * *}$ & $-10.932^{* * *}$ \\
\hline
\end{tabular}

Notes. Z(t-bar) istatistiği modellerde sabit değişkenler kullanarak tahmin yapmaktadır. ${ }^{*} 10$ düzeyinde istatistiki olarak anlamlılığ1 göstermektedir. $* * \% 5$ düzeyinde istatistiki olarak anlamlılığı göstermektedir. ***\%1 düzeyinde istatistiki olarak anlamlılığı göstermektedir.

Tablo 2'deki sonuçlara göre, değişkenlerin farklı gecikme seviyelerinde ve farklı hata paylarında durağan olduğu görülmektedir. Düzey değerinde durağan olmayan değişkenler de bulunmaktadır. Fakat değişkenlerin birinci farkı alındığında tüm gecikme seviyelerinde durağanlık sağlanmaktadır. Bu durum eşbütünleşme ilişkisinin sorgulanmasına uygun veriye sahip olunduğunu göstermektedir.

\subsection{Panel Eşbütünleşme Testi}

Westerlund (2007) panel eşbütünleşme testi sonuçları Tablo 3'te yer almaktadır.

Tablo 3. Panel Eşbütünleşme Testi Sonuçları

\begin{tabular}{|c|c|c|c|c|c|}
\hline & Test & Test Değeri & Z-değeri & P-değeri & Dirençli P-değeri \\
\hline \multirow{4}{*}{ Sabit } & $\mathrm{Gt}$ & -3.506 & -3.573 & 0.000 & 0.010 \\
\cline { 2 - 6 } & $\mathrm{Ga}$ & -27.888 & -6.689 & 0.000 & 0.005 \\
\cline { 2 - 6 } & $\mathrm{Pt}$ & -6.219 & -2.313 & 0.010 & 0.033 \\
\cline { 2 - 6 } & $\mathrm{Pa}$ & -16.464 & -4.239 & 0.000 & 0.058 \\
\hline \multirow{5}{*}{ Sabit ve Trend } & $\mathrm{Gt}$ & -3.924 & -3.712 & 0.000 & 0.015 \\
\cline { 2 - 6 } & $\mathrm{Ga}$ & -33.478 & -6.053 & 0.000 & 0.018 \\
\cline { 2 - 6 } & $\mathrm{Pt}$ & -7.033 & -2.126 & 0.017 & 0.113 \\
\cline { 2 - 6 } & $\mathrm{Pa}$ & -21.425 & -3.618 & 0.000 & 0.225 \\
\hline
\end{tabular}

Notes. Gecikme uzunluğu ve öncül uzunluğu AIC bilgi kriterine göre belirlenmiştir. Önyükleme hatası 400 tekrara dayanmaktadır.

Tablo 3'teki test sonuçlarına göre sabitli modelde dirençli olasılık değerlerinde Gt testinde \%5 hata payı, Ga testinde $\% 1$ hata payı, $\mathrm{Pt}$ testinde $\% 5$ hata payı ve Pa testinde $\% 10$ hata payı ile eşbütünleşme ilişkisi olmadığına dair $\mathrm{H}_{0}$ hipotezi reddedilmiş, eşbütünleşme ilişkisi olduğuna dair $\mathrm{H}_{1}$ hipotezi kabul edilmiştir. Sabitli ve trendli modellerde ise direçli olasılık değerlerinde yalnızca Gt ve Ga testinde \%5 hata payı ile eşbütünleşme ilişkisi olmadığına dair $\mathrm{H}_{0}$ hipotezi reddedilmiş, eşbütünleşme ilişkisi olduğuna dair $\mathrm{H}_{1}$ hipotezi kabul edilmiştir. Pt ve Pa testlerinde ise eşbütünleşme ilişkisi olmadığına dair $\mathrm{H}_{0}$ hipotezi kabul edilmiş, eşbütünleşme ilişkisi olduğuna dair $\mathrm{H}_{1}$ hipotezi reddedilmiştir. Yapılan testlerin çoğunda seriler arasında eşbütünleşme ilişkisi olduğu görülmektedir. Bu durum değişkenlerin uzun dönemde birlikte hareket ettiğini göstermektedir.

\subsection{Panel Eşbütünleşme Regresyonları}

Eşbütünleşme ilişkisi bulunan değişkenler arasında uzun ve kısa dönem katsayıların bulunması için kullanılacak yönteme karar vermek için Hausman testi uygulanmaktadır. Hausman testi sonuçları Tablo 4'te yer almaktadır. 
B. Kaya $12 / 1$ (2020) 705-714

Tablo 4. Hausman Testi Sonuçları

\begin{tabular}{|l|c|c|c|c|}
\hline & \multicolumn{3}{|c|}{ Katsayılar } & \\
\hline & $\begin{array}{c}(\mathrm{b}) \\
\mathrm{mg}\end{array}$ & $\begin{array}{c}\text { (B) } \\
\text { pmg }\end{array}$ & $\begin{array}{c}(\mathrm{b}-\mathrm{B}) \\
\text { Difference }\end{array}$ & $\begin{array}{c}\text { sqrt(diag(V_b-V_B }) \\
\text { S.E. }\end{array}$ \\
\hline lnalış & 0.9030481 & 1.157342 & -0.2542938 & 0.2527766 \\
\hline lnsatış & -0.7929778 & -0.9657572 & 0.1727794 & 0.2144843 \\
\hline \multicolumn{4}{|c|}{ Prob>chi ${ }^{2}=0.0628$} \\
\hline
\end{tabular}

Tablo 4'teki sonuçlara göre \% 5 hata payı ile $\mathrm{H}_{0}$ hipotezi reddedilememiştir. $\mathrm{H}_{0}$ hipotezi altında daha etkili olan Havuzlanmış Ortalama Grup Tahmincisinin kullanılmasına karar verilmiştir (Tatoğlu, 2013:256).

Havuzlanmış Ortalama Grup Tahmincisi metoduna göre ulaşılan test sonuçları Tablo 5 'te yer almaktadır.

Tablo 5. Havuzlanmış Ortalama Grup Tahmincisi Testi Sonuçları

\begin{tabular}{|c|c|c|c|c|c|c|}
\hline D.lnfiyat & Katsay 1 & $\begin{array}{c}\text { Standart } \\
\text { Hata }\end{array}$ & $\mathrm{z}$ & $P>|z|$ & \multicolumn{2}{|c|}{ [95\% Güven Aralığı] } \\
\hline \multicolumn{7}{|l|}{$\begin{array}{c}\text { Uzun dönem } \\
\text { ec }\end{array}$} \\
\hline lnalış & 1.1573 & 0.2404 & 4.81 & 0.000 & 0.6861 & 1.6286 \\
\hline lnsatış & -0.9658 & 0.2372 & -4.07 & 0.000 & -1.4306 & -0.5008 \\
\hline Kısa dönem & & & & & & \\
\hline ec & -0.1547 & 0.4413 & -3.51 & 0.000 & -0.2412 & -0.0682 \\
\hline lnalışD1. & 0.1008 & 0.0322 & 3.13 & 0.002 & 0.0377 & 0.1639 \\
\hline lnssatışD1. & -0.0339 & 0.0245 & -1.38 & 0.167 & -0.0820 & 0.0142 \\
\hline _sabit & -0.3381 & 0.1031 & -3.28 & 0.001 & -0.5402 & -0.1360 \\
\hline
\end{tabular}

Tablo 5 'teki test sonuçlarına göre hata düzeltme parametresi $(-0.1547)$ negatif ve anlamlıdır. Bu durum değişkenler arasındaki uzun dönemli bir ilişkinin varlığını teyit etmektedir. Hata düzeltme parametresi serilerin durağan olmamasından kaynaklanan kısa dönem sapmalarının bir sonraki dönem dengeye gelme hızını göstermektedir (Tatoğlu, 2013:245). Bu durumda bir dönemde oluşan dengesizliklerin yaklaşık \%15'i bir sonraki dönemde düzelecek ve uzun dönem dengesine yaklaşması sağlanacaktır. lnalış değişkeninin uzun dönem katsayısı pozitif ve istatistiki olarak anlamlıdır. lnsatış değişkenin de uzun dönem katsayısı negatif ve istatistiki olarak anlamlıdır. Bu sonuç, uzun dönemde yabancı yatırımcı alışlarındaki \%1'lik artışın hisse fiyatlarını \%1,15 artırdığını, yabancı yatırımcı satışlarındaki \%1'lik artışın hisse fiyatlarını \%0,96 düşürdügünü göstermektedir. Kısa dönem katsayılarına bakıldığında ise lnalış değişkenin katsayısı pozitif ve istatistiki olarak anlamlıdır. Insatış değişkenin katsayısı ise negatif olmasına rağmen istatistiki olarak anlamlı değildir. Bu sonuca göre kısa dönemde yabancı yatırımcı alışlarındaki \%1'lik artış hisse fiyatlarını \%0,10 artırmaktadır.

Havuzlanmış Ortalama Grup Tahmincisi birimlere ilişkin uzun ve kısa dönem katsayılara ilişkin bilgileri de sağlamaktadır. Birimlere ilişkin test sonuçları Tablo $6^{\prime}$ da gösterilmektedir. 
B. Kaya $12 / 1$ (2020) 705-714

Tablo 6. Birimlere Ait Havuzlanmış Ortalama Grup Tahmincisi Testi Sonuçları

\begin{tabular}{|c|c|c|c|c|c|c|}
\hline D.lnfiyat & Katsayı & $\begin{array}{c}\text { Standart } \\
\text { Hata }\end{array}$ & $\mathrm{z}$ & $P>|z|$ & $\begin{array}{c}\text { [95\% Güven } \\
\text { Aralığı] }\end{array}$ & Katsay1 \\
\hline \multicolumn{7}{|l|}{ Şirket_14 } \\
\hline _ec & -0.1932 & 0.0352 & -5.49 & 0.000 & -0.6861 & 1.6286 \\
\hline lnalışD1. & 0.0621 & 0.0424 & 1.46 & 0.143 & -0.0210 & 0.1451 \\
\hline lnsatışD1. & -0.0275 & 0.0426 & -0.65 & 0.518 & -0.1110 & 0.0559 \\
\hline _sabit & -0.3635 & 0.1113 & -3.26 & 0.001 & -0.5817 & -0.1453 \\
\hline \multicolumn{7}{|l|}{ Şirket_25 } \\
\hline _ec & -0.0086 & 0.0078 & -1.10 & 0.272 & -0.0239 & 0.0067 \\
\hline lnalışD1. & 0.0145 & 0.0078 & 1.88 & 0.061 & -0.0007 & 0.0297 \\
\hline $\begin{array}{l}\text { lnsatışD1. } \\
\text { sabit }\end{array}$ & 0.0118 & 0.0072 & 1.64 & 0.100 & -0.0023 & 0.0259 \\
\hline \multicolumn{7}{|l|}{ Şirket_36 } \\
\hline _ec & -0.2527 & 0.0387 & -6.52 & 0.000 & -0.3286 & -0.1768 \\
\hline lnalışD1. & 0.0844 & 0.0711 & 1.19 & 0.235 & -0.0550 & 0.2238 \\
\hline lnsatışD1. & -0.0132 & 0.0674 & -0.20 & 0.844 & -0.1453 & 0.1188 \\
\hline _sabit & -0.5658 & 0.1637 & -3.46 & 0.001 & -0.8866 & -0.2450 \\
\hline \multicolumn{7}{|l|}{ Şirket_47 } \\
\hline _ec & -0.1026 & 0.0229 & -4.49 & 0.000 & -0.1474 & -0.0578 \\
\hline lnalışD1. & 0.1992 & 0.0386 & 5.16 & 0.000 & 0.1236 & 0.2748 \\
\hline lnsatışD1. & -0.1288 & 0.0374 & -3.44 & 0.001 & -0.2021 & -0.0555 \\
\hline _sabit & -0.2164 & 0.0643 & -3.37 & 0.001 & -0.3424 & -0.0904 \\
\hline \multicolumn{7}{|l|}{ Şirket_58 } \\
\hline _ec & -0.2163 & 0.0359 & -6.03 & 0.000 & -0.2866 & -0.1460 \\
\hline lnalışD1. & 0.1438 & 0.0596 & 2.41 & 0.016 & 0.0269 & 0.2606 \\
\hline lnsatışD1. & -0.0117 & 0.0597 & -0.20 & 0.844 & -0.1287 & 0.1052 \\
\hline _sabit & -0.5340 & 0.1359 & -3.93 & 0.000 & -0.8004 & -0.2677 \\
\hline
\end{tabular}

Tablo 6'daki sonuçlara göre tek bir uzun dönem parametresi tahmin edilmiş fakat hata düzeltme parametresi, kısa dönem parametreleri ve sabit parametreler birimlere göre değişmektedir. Akbank T.A.Ş., Türkiye Garanti Bankası A.Ş., Türkiye İş Bankası A.Ş. ve Yapı ve Kredi Bankası A.Ş.'nin hata düzeltme parametresi negatif ve istatistiki olarak anlamlıdır. Bu durum değişkenler arasında uzun dönemli ilişkinin varlığını göstermektedir. Akbank T.A.Ş.'de kısa dönemde meydana gelen sapmaların \%19'u, Türkiye Garanti Bankası A.Ş.'de \%25'i, Türkiye İş Bankası A.Ş.'de \%10'u, Yapı ve Kredi Bankası A.Ş.'de \%21'i bir dönemde uzun dönem dengesine yaklaşmaktadır. Kısa dönem katsayılarına bakıldığında ise, QNB Finansbank A.Ş.'de lnalış değişkeni pozitif ve \%10 hata payı ile istatistiki olarak anlamlıdır. Türkiye İş Bankası A.Ş.'de lnalış değişkeni pozitif ve \%1 hata payı ile, lnsatış değişkeni negatif ve \%1 hata payı ile istatistiki olarak anlamlıdır. Yapı ve Kredi Bankası A.Ş.'de lnalış değişkeni pozitif ve $\% 5$ hata payı ile istatistiki olarak anlamlıdır. Bu sonuçlara göre kısa dönemde QNB Finansbank A.Ş.'de yabancı yatırımcı alışlarındaki \%1 artış hisse fiyatlarını \%0,0145 artırmaktadır. Türkiye İş Bankası A.Ş,'de yabancı yatırımcı alışlarındaki \%1 artış hisse fiyatlarını \%0,19 artırmakta, yabancı yatırımcı satışlarındaki \%1 artış hisse fiyatlarını \%0,12 azaltmaktadır. Yapı ve Kredi Bankası A.Ş.'de yabancı yatırımcı alışlarındaki \%1 artış hisse fiyatlarını \%0,14 artırmaktadır.

\subsection{Heterojen Panel Nedensellik Testi}

Dumitrescu ve Hurlin (2012) heterojen panel nedensellik testi sonuçları Tablo 7'te yer almaktadır.

\footnotetext{
${ }^{4}$ Akbank T.A.Ş.

${ }^{5}$ QNB Finansbank A.Ş.

${ }^{6}$ Türkiye Garanti Bankası A.Ş.

7 Türkiye İş Bankası A.Ş.

${ }^{8}$ Yapı ve Kredi Bankası A.Ş.
} 
Tablo 7. Heterojen Panel Nedensellik Testi Sonuçları

\begin{tabular}{|l|c|c|c|}
\hline \multicolumn{1}{|c|}{ Ho Hypothesis } & $\begin{array}{c}\text { W- } \\
\text { İstatistiği }\end{array}$ & $\begin{array}{c}\text { Zbar- } \\
\text { İstatistiği }\end{array}$ & Olasılık \\
\hline lnalış, lnfiyat nedeni değildir. & 4.99972 & 6.21133 & $5 . \mathrm{E}-10$ \\
\hline lnfiyat, lnalış nedeni değildir. & 1.74943 & 1.15243 & 0.2491 \\
\hline lnsatış, lnfiyat nedeni değildir. & 4.83547 & 5.95568 & $3 . \mathrm{E}-09$ \\
\hline lnfiyat, lnsatış nedeni değildir. & 2.98912 & 3.08194 & 0.0021 \\
\hline lnsatış, lnalış nedeni değildir. & 10.0240 & 14.0314 & 0.0000 \\
\hline lnalış, lnsatış nedeni değildir. & 21.6960 & 32.1982 & 0.0000 \\
\hline
\end{tabular}

Tablo 7'deki sonuçlara göre lnfiyat değişkeni lnsatış değişkeninin \%1 hata payı ile nedeni iken lnalış değişkeninin nedeni değildir. lnalış ve lnsatış değişkenleri arasında ise \%1 hata payı ile çift yönlü nedensellik ilişkisi bulunmaktadır.

\section{SONUÇ VE TARTIŞMA}

Bu çalışmada Türkiye'nin menkul kıymetler borsasında (Borsa İstanbul) Ocak 2000-Aralık 2018 arasındaki dönemde aylık veriler kullanılarak BIST BANKA endeksi kapsamındaki bankalar ölçeğinde yabancı yatırımcılar tarafından gerçekleştirilen alış-satış işlemleri ile hisse fiyatları arasındaki ilişki incelenmiştir. Westerlund (2007) panel eşbütünleşme testi sonuçlarına göre, yabancı yatırımcıların alış-satış işlemleri ile hisse fiyatları arasında eşbütünleşme ilişkisi bulunmaktadır. Havuzlanmış Ortalama Grup Tahmincisi sonuçlarına göre uzun dönemde yabancı yatırımcı alışları hisse fiyatlarını artırmakta, satışları hisse fiyatlarını düşürmektedir. Kısa dönemde ise yalnızca yabancı yatırımcı alışları hisse fiyatlarını artırmaktadır. Yabancı satışlarının hisse fiyatları üzerinde istatistiki olarak anlamlı bir ilişkisi tespit edilememiştir. Dumitrescu and Hurlin (2012) heterojen panel nedensellik testi sonuçları, yabancı yatırımcı alış ve satış işlemlerinin hisse fiyatlarının nedeni olmadığını, fakat hisse fiyatlarının yabancı yatırımcı satış işlemlerinin nedeni olduğunu göstermektedir. Ulaşılan sonuçlar literatürde yer verilen çalışmalardan Chiang vd. (2012), Bolaman Avcı (2015) ile de tutarlıdır. Bundan sonra yapılacak çalışmalarda dengesiz panellerin kullanılması, bu çalışmanın kısıtını ortadan kaldırarak literatüre katkı sağlayacaktır.

\section{KAYNAKÇA}

Akar, C. (1997). Yabancılar Türkiye'de pozitif geri besleme hipotezine uygun davranışlar gösterirler mi?, IMKB Dergisi, Cilt 10, Sayı, 39, 61-67.

Bai, J. and Ng, S. (2004). A panic attack on unit roots and cointegration, Econometrica, Vol. 72, No:4, 1127-1177.

Baltagi, B. H, Feng, Q., and C. Kao (2012). A lagrange multiplier test for cross-sectional dependence in a fixed effects panel data model, Journal of the Econometrics, 170, 164-177.

Breitung, J. (2000). The local power of some unit root tests for panel data, In Advances in Econometrics, Vol. 15, 161-178.

Bolaman Avcı, Ö. (2015). Effect of foreign investor transactions on stock market returns, Hacettepe University Journal of Economics and Administrative Sciences, Vol. 33, Issue 4, 29-38.

Breusch, T., and Pagan A. (1980). The lagrange multiplier test and its application to model specification in econometrics, Review of Economic Studies, 47, 239-253.

Burret, H. T., Feld, L. P. and Köhler, E. A. (2016). (Un-) Sustainability of public finances in German laender: A panel time series approach, Economic Modelling, 53, 254-265.

Chiang, S. J., Tsai, L.J., Shu, P. G. and Chen, S.L., (2012). The trading behavior of foreign, domestic institutional, and domestic individual investors: Evidence from the Taiwan stock market, Pacific-Basin Finance Journal, 20, 745-754.

Choe, H., Kho, B. C. and Stulz, R. M., (1999). Do foreign investors destabilize stock markets? The Korean experience in 1997, Journal of Financial Economics, 54, 227-264. 


\section{B. Kaya 12/1 (2020) 705-714}

Dhingra, V. S., Gandhi, S. and Bulsara, H. P. (2016). Foreign institutional investments in India: An empirical analysis of dynamic interactions with stock market return and volatility, IIMB Management Review, 28, 212-224.

Dumitrescu, E. I. and Hurlin C. (2012). Testing for granger non-causality in heterogeneous panels, Economic Modeling, 29, 1450-1460.

Hadri, K. (2000). Testing for stationarity in heterogeneous panel data, Econometrics Journal, Vol. 3, 148-161.

Harris R. D. F. and Tzavalis E. (1999). Inference for unit roots in dynamic panels where the time dimension is fixed, Journal of Econometrics, 91, 201-226.

https://datastore.borsaistanbul.com/ , Erişim Tarihi: 30/04/2019.

Im K. S., Pesaran M. H. and Shin Y. (2003). Testing for unit roots in heterogeneous panels, Journal of Econometrics, Vol. 115, 53-74.

Junior, W. G. and Junior, W. E. (2017). Sophistication and price impact of foreign investors in The Brazilian Stock Market, Emerging Markets Review, 33, 102-139.

Jeon, J. Q. and Moffett, C. M. (2010). Herding by foreign investors and emerging market equity returns: Evidence from Korea, International Review of Economics and Finance, 19, 698-710.

Kao, C. (1999). Spurious regression and residual-based tests for cointegration in panel data, Journal of Econometrics, Vol. 90, 1-44.

Levin, A., Lin, C. F. and Chu, C. S. J. (2002). Unit root tests in panel data: Asymptotic and finite-sample properties, Journal of Econometrics, 108, 1-24.

Maddala G. S. and Wu, S. (1999). A comparative study of unit root tests with panel data and new simple test, Oxford Bulletin of Economics and Statistics, 61, 631-652.

McCoskey, S. and Kao, C. (1998). A residual-based test of the null of cointegration in panel data, Econometric Reviews, 17(1), 57-84.

Merkezi Kayıt Kuruluşu, Borsa Trenleri Raporları, XXVII, Erişim: https://www.mkk.com.tr/tr/content/BilgiMerkezi/Borsa-Trendleri-Raporu, Erişim Tarihi: 11.06.2019.

Moon, H. R. and Perron, B. (2004). Testing for a unit root in panels with dynamic factors, Journal of Econometrics, Vol. 122, 81-126.

Nofsinger, J. R. and Sias, R. W. (1999). Herding and feedback trading by institutional and individual investors, The Journal of Finance, Vol LIV, No 6, 2263-2295.

Paramati, S. R., Shahbaz, M. and Alam Md. S. (2017). Does tourism degrade environmental quality? A comparative study of Eastern and Western European Union, Transportation Research Part D, Vol. 50, 113.

Pedroni, P. (1999). Critical values for cointegration tests in heterogeneous panels with multiple regressors, Oxford Bulletin of Economics and Statistics, Vol. 61, 653-670.

Pedroni, P. (2000). Fully modified ols for heterogeneous countegrated panels, Advances in Econometrics, Vol. $15,93-130$.

Pedroni, P. (2004). Panel cointegration: asymptotic and finite sample properties of pooled time series tests with application to the ppp hypothesis, Econometric Theory, Vol. 20, 597-625.

Pesaran M. H. and Smith R. (1995). Estimating long-run relationships from dynamic heterogeneous panels, Journal of Ecoonometrics, 68 (1), 79-113.

Pesaran, M. H. (2004). General diagnostic tests for cross section dependence in panels, University of Cambridge, Faculty of Economics, Cambridge Working Papers in Economics No. 0435. 
B. Kaya 12/1 (2020) 705-714

Pesaran, M. H. (2007). A simple panel unit root test in the presence of cross-section dependence, Journal of Applied Econometrics, Vol. 22, 265-312.

Pesaran M. H., Shin Y. and Smith R. P. (1999). Pooled mean group estimation of dynamic heterogeneous panel, Journal of the American Statistical Association, 94, 621-634.

Phansatan, S., Powell, J. G., Tanthanongsakkun, S. and Treepongkaruna, S. (2012). Investor type trading behavior and trade performance: evidence from The Thai Stock Market, Pacific-Basin Finance Journal, 20, 1-23.

Philips P. C. B. and Moon H. R. (2000). Nonstationary panel data analysis: an overview of some recent developments, Econometric Reviews, 19 (3), 263-286.

Phillips, P. C. B. and Sul, D. (2002). Dynamic panel estimation and homogeneity testing under cross section dependence, Econometrics Journal, Vol. 6, 217-259.

Porras, E. and Ülkü, N. (2015). Foreigners' trading and stock returns in Spain, Journal of International Financial Markets, Institutions \& Money, 34, 111-126.

Samarakoon, L. P. (2009). The relation between traders of domestic and foreign investors and stock returns in Sri Lanka, Journal of International Financial Markets, Institutions \& Money, 19, 850-861.

Stock, J. H. and Watson, M. (1993). A simple estimator of cointegrating vectors in higher order integrated systems, Econometrica, 61, 783-820.

Tatoğlu, F. Y. (2013). İleri Panel Veri Analizi, Beta, 2. Baskı.

Ülkü, N. and İkizlerli, D. (2012). The interaction between foreigners' trading and emerging stock returns: evidence from Turkey, Emerging Markets Review, 13, 381-409.

Ülkü, N. (2015). The interaction between foreigners' trading and stock market returns in Emerging Europe, Journal of Empirical Finance, 33, 243-262.

Vo, X. V. (2017). Trading of foreign investors and stock returns in an emerging market-evidence from Vietnam, International Review of Financial Analysis, 52, 88-93.

Westerlund, J. (2007). Testing for error correction in panel data, Oxford Bulletin of Economics and Statistics, Vol. $69,709-748$. 